\title{
Groups as Moral Boundaries: A Developmental Perspective
}

Lisa Chalik ${ }^{1} \&$ Marjorie Rhodes ${ }^{2}$

${ }^{1}$ Department of Psychology, Yeshiva University

${ }^{2}$ Department of Psychology, New York University

Funding was provided by a Scholars Award from the James S. McDonnell Foundation to Rhodes.

Correspondence may be addressed to Lisa Chalik, lisa.chalik@yu.edu, Stern College for Women, 215 Lexington Avenue, New York, NY 10016.

[Chapter to appear in J. Benson (Ed.), Advances in Child Development and Behavior, Vol. 58] 


\begin{abstract}
In this chapter we present the perspective that social groups serve as moral boundaries. Social groups establish the bounds within which people hold moral obligations toward one another. The belief that people are morally obligated toward fellow social group members, but not toward members of other groups, is an early-emerging feature of human cognition, arising out of domain-general processes in conceptual development. We review evidence that supports this account from the adult and child moral cognition literature, and we describe the developmental processes by which people come to view social groups as shaping moral obligation. We conclude with suggestions about how this account can inform the study of social cognitive development more broadly, as well as how it can be used to promote positive moral socialization.
\end{abstract}

Keyword list - social cognitive development, intergroup cognition, social categorization, moral cognition, conceptual development, domain-general processes, socialization, social relationships, developmental processes, moral philosophy 
"Act in such a way that you treat humanity, whether in your own person or in the person of any other, never merely as a means to an end, but always at the same time as an end." -Immanuel Kant, 1785

"The only purpose for which power can be rightfully exercised over any member of a civilized community, against his will, is to prevent harm to others."

-John Stuart Mill, 1854

"Only the development of compassion and understanding for others can bring us the tranquility and happiness we all seek."

-Dalai Lama XIV, 1998

These quotations illustrate core tenants of human morality that entail protecting one another from harm. Moral rules dictate how people ought to treat each other to prevent harm and promote social harmony. These seem to be simple ideas, yet a question remains: Who are the "others" that these rules speak of? The quotes here do not specify any characteristics of the "others." Does this imply that people hold moral obligations toward all other humans, and perhaps even all other living things? Research on the psychology of morality suggests that this is often not how people think or behave. On the contrary, in any given situation, people seem to view the application of moral obligations differently depending on the people involved. How do people determine who is worthy of moral consideration, and who is not?

We propose that social groups provide the answer to this question. In human psychology, groups serve as "moral boundaries," marking individuals who do and do not hold moral obligations toward one another. To support for this proposal, we will first review evidence from broad theoretical accounts of human morality, as well as from empirical tests of adult moral cognition. Next, we will discuss how concerns for social groups might be integrated with moral 
cognition across development, and will provide evidence that viewing groups as moral boundaries is an early-emerging feature of human cognition. We will then review the potential developmental processes by which the belief in groups as moral boundaries might emerge in the first few years after birth by proposing that this belief originates from domain-general features of conceptual development. Finally, we will discuss the implications of our perspective for the study of social cognitive development and for the facilitation of positive moral socialization.

\section{What does it mean for groups to serve as moral boundaries?}

Children quickly learn that dogs are supposed to bark, that parents ought to take care of children, and that forks should be used for eating (and not for combing hair). These examples illustrate how categories (of objects, animals, or people) are a fundamental lens through which humans view the world. Right from the start, children view these categories as not only describing, but also prescribing what their members do. That is, not only do dogs usually bark, but they are supposed to do so, and there is something amiss about one that does not (note that when we use the words "supposed to", we are referring to how people think the world is supposed to be, rather than making philosophical claims about how the world is supposed to be in reality; Haward, Wagner, Carey, \& Prasada, 2018; Prasada \& Dillingham, 2009). In the social world, then, categories prescribe how people are supposed to behave. For example, these prescriptions might include beliefs that girls should wear pink, boys shouldn't cry, firefighters should save people, and doctors should take care of people who are sick (Foster-Hanson \& Rhodes, 2019b).

At their most basic, social groupings specify how their members are supposed to treat one another. For example, imagine seeing two people at an American political rally, both wearing pro-Democrat t-shirts. It would likely not be surprising if, upon seeing each other, these two 
people ran toward one another and hugged. Would it be more surprising, however, to see the two people hug if one of them were wearing a pro-Republican shirt? This simple example illustrates how people expect social groups to determine how people treat one another- that people will be friendly to and support members of their own groups, but not necessarily members of other groups. But because categories not only describe their members' behavior but also prescribe them (Roberts, Gelman, \& Ho, 2017; Roberts, Ho, \& Gelman, 2017), people's beliefs in these situations go deeper. For example, they think that people ought to treat members of their own groups more positively than members of other groups. Thus, groups shape beliefs about the obligations that people hold toward one another. People within the same social group boundaries are morally obligated to protect and avoid harm to one another, but these obligations do not extend across social group boundaries.

Evolutionary psychologists and anthropologists have long argued that morality evolved as a way to coordinate human action in an intergroup landscape (Boyd \& Richerson, 2009; Gintis, Bowles, Boyd, \& Fehr, 2003; Greene, 2013; Rand \& Nowak, 2013; Trivers, 1971). This perspective argues that to succeed in the tribal environments in which humans evolved, humans needed to suppress a natural tendency toward self-preservation in order to cooperate with and protect those around them. Consequently, moral norms and emotions evolved as a way of ensuring that people would not perform selfish actions that would harm the overall well-being of the tribe (e.g., Moll, De Oliveira-Souza, \& Eslinger, 2003). It follows that the moral concerns that evolved as part of this system would be viewed as applying only within group boundaries. For example, for a hunter-gatherer, it would have been beneficial to share food with fellow tribe members, even though this would reduce the amount of food available for oneself, because a norm of sharing food would ensure that everyone in the tribe will always be able to eat, even in 
times of scarcity. The feeling that it is praiseworthy to share food with fellow tribe members, however, should not facilitate any beliefs about performing that same sharing behavior toward members of other tribes. In fact, sharing with other tribes may even be viewed as blameworthy, given that it reduces the resources available to the tribe and potentially puts the tribe in a worse position. All of this is to say that because concerns for morality evolved to support coordination within groups, an inherent part of this morality is that good acts are only viewed as praiseworthy and bad acts are only viewed as blameworthy if they occur among fellow group members. In other words, social groups establish the boundaries within which moral concerns are thought to apply.

\section{Support from theories of morality}

The idea that groups serve as moral boundaries has been ubiquitous in theories of morality that have been put forth by philosophers, psychologists, and anthropologists. For example, in attempts to describe the scope of human moral thought, many have argued that "moral circles" define the boundaries within which we extend moral concern to others (Laham, 2009; Singer, 1981; Ting, Dawkins, Stavans, \& Baillargeon, 2019), implying that people naturally divide the social world into those who are worthy of moral consideration and those who are not. Others have described a "scope of justice," again defining the boundaries within which people are "morally included" and deserving of fair treatment; those outside the scope of justice are excluded from moral concern, and thus become eligible for harmful or unfair treatment (Clayton \& Opotow, 2003; Opotow, 2012; Staub, 1990).

The idea that groups factor into the moral evaluation system has also been a central component of various theories that attempt to describe the content of moral thought. For example, in a seminal anthropological theory of morality, Shweder and his colleagues proposed 
three distinct moral codes, each based on a different conceptualization of the individual, that exist universally and are used to evaluate moral issues (Shweder, Mahapatra, \& Miller, 1990; Shweder, Much, Mahapatra, \& Park, 1997). One of these codes is "the ethics of community," by which people evaluate moral action based on whether a person is carrying out their duties within a community (in other words, their obligations toward the group). Complimenting this theory, some have argued that certain moral emotions evolved in order to enforce the ethics of community. Specifically, the emotion of contempt may have evolved as an expression of distaste for community violations, given that it often is felt by members of one group who feel that members of another group are inferior (Rozin, Lowery, Haidt, \& Imada, 1999).

Another influential theory of morality was put forth by Jonathan Haidt, who argued for six moral "foundations" that serve as an innate first draft of the human moral code (Haidt \& Graham, 2007; Haidt \& Joseph, 2004, 2007). From this account, humans evolved to be on the lookout for violations of each of the six foundations, and individual cultures construct their own narratives to specify which foundations are most relevant to the local morality. Most relevant here is the foundation of ingroup loyalty, which regards trusting and cooperating with members of the ingroup and being wary of members of the outgroup. To enforce this foundation, people's moral emotions lead them to value loyalty and sacrifice for the ingroup and to prohibit betrayal and failures to help the ingroup.

As a final example, Rai and Fiske (2011) suggested a model of morality that relies on relationship regulation. They posit that humans hold four moral motives that can be employed to judge any social action, depending on the relationships among the people involved. The first of these motives is unity, which involves supporting the integrity of the ingroup through collective responsibility. Thus, if someone in the group needs help, other members of the group are 
required to provide it. Additionally, if someone in the group transgresses, the entire group bears responsibility, and if someone in the group is harmed, the whole group must respond on the harmed individual's behalf.

This is not an exhaustive list of the theories of morality. Yet, this brief survey illustrates a broad consensus across scholars from diverse perspectives and traditions that considerations about social groups are a central component of human moral cognition.

\section{Evidence from research on adult moral cognition}

In addition to theoretical proposals, there is a great deal of experimental evidence in the adult moral psychology literature to suggest that groups serve as moral boundaries. First, social groups play a clear role in shaping people's moral behavior. Across a range of experimental paradigms, people cooperate more with ingroup members than with outgroup members (Brewer, 2007; Brewer \& Kramer, 1986; Hackel, Zaki, \& Van Bavel, 2017; Tajfel, Billig, Bundy, \& Flament, 1971; Yamagishi \& Kiyonari, 2006), even if those ingroup members are anonymous (Burkart, Hrdy, \& Van Schaik, 2009). People are more likely to help ingroup than outgroup members in cases of natural disaster (Levine \& Thompson, 2004) and physical violence (Levine, Cassidy, Brazier, \& Reicher, 2002), and people show more aggression toward others when they are presented as members of an outgroup, rather than as individuals (Meier \& Hinsz, 2004). People may even value negativity toward outgroup members: Viewing harm against outgroup members is associated with the activation of brain regions that encode reward (Cikara, Botvinick, \& Fiske, 2011).

But are these behaviors the result of moral concerns? Research on moral emotions suggests that this is indeed the case. The manipulation of moral emotions, such as empathy, differentially shapes people's behavior toward ingroup and outgroup members. For example, 
people who have been instructed to be empathic toward the ingroup are more competitive in later intergroup interactions (Cohen, Montoya, \& Insko, 2006), and people who rate higher on parochial empathy (empathy for the ingroup, rather than the outgroup) are more likely to withhold charitable donations from and endorse harm toward the outgroup (Bruneau, Cikara, \& Saxe, 2017). Empathic concern can even have quite extreme consequences in contexts of intergroup war: Israelis and Palestinians who rate higher on empathy for their own communities are more likely to endorse harm toward the outgroup (Ginges \& Atran, 2009), and individuals who show more communal concern for their ingroup are more likely to endorse extreme acts of outgroup aggression, such as terrorism and rebellion (Argo, 2009).

Furthermore, there is evidence that people often withhold moral consideration from outgroup members. In a particularly clear test of this proposal, Voelket and Brandt (2019) asked participants to respond to a version of the Moral Foundations Questionnaire (Graham, Haidt, \& Nosek, 2009) that had been manipulated to target either liberals or conservatives. They found that both conservative and liberal participants were more likely to endorse the moral foundations when answering questions about acts that targeted political ingroup versus outgroup members (i.e., conservatives more highly valued caring for others and avoiding harm to others when those others had been described as fellow conservatives). Similarly, Frimer and colleagues (2014) found that whether people view obedience as a moral value depends on the group memberships of the people involved: Conservatives value obedience more when it involves conservative authority figures (e.g., a religious authority), and liberals value obedience more when it involves liberal authority figures (e.g., a civil rights activist).

Concerns for social groups have also been documented with traditional measures of moral judgment, such as trolley dilemmas. In these dilemmas, which ask whether it is 
permissible to sacrifice one life in order to save five others, participants are more likely to endorse sacrificing one life to save five if the people to be saved are ingroup members, rather than outgroup members (Cikara, Farnsworth, Harris, \& Fiske, 2010). Furthermore, when asked whether they would sacrifice themselves to save the lives of others, participants who strongly identify with the group endorse sacrificing their own lives to save ingroup members, but not outgroup members (Swann, Gómez, Huici, Morales, \& Hixon, 2010).

This research supports the view that adult moral cognition is shaped by concerns for social groups. Next, we turn to the developmental origins of these beliefs.

\section{How are groups integrated into moral cognition across development?}

\section{Theoretical perspectives}

There are two main possibilities as to how social groups might be integrated into moral cognition across development. One possibility is that concerns for morality and concerns for group membership develop independently of one another, and only interact once children have extended experience with the social groups in their environment (Abrams, Rutland, Pelletier, \& Ferrell, 2009; Rutland \& Killen, 2017; Rutland, Killen, \& Abrams, 2010). From this account, children hold an early-emerging sense of morality that consists of concerns for justice and fairness, regardless of the characteristics (e.g., group membership) of the people involved. Then, once children reach middle childhood and, through extended experiences in social groups, have developed a more complex understanding of how groups generally function, they begin to incorporate concerns for group membership into their moral evaluations, especially in instances where groups have been made salient to them. This shift has been explained as being a result of the development of a "theory of social mind" between ages 7 and 8 , by which children rely on their experiences with their peers to come to understand that the interests of the group are not 
always the same as those of the individual (Abrams et al., 2009; Ongley \& Malti, 2014; Rutland, 2013). As evidence for this proposal, children increasingly integrate group concerns into their moral concerns across development. For example, the extent to which children expect loyalty norms to shape group dynamics increases between early childhood and adolescence (Abrams \& Rutland, 2008; Abrams, Rutland, Cameron, \& Marques, 2003; Abrams et al., 2009).

Furthermore, when preschool-age children evaluate the resource-allocation norms of their peer groups, they prioritize equal allocation over allocation in favor of the ingroup, suggesting that they often prioritize moral concerns, such as fairness, over supporting the ingroup (Cooley \& Killen, 2015). However, as children grow into adolescence, they begin to view ingroup-favoring allocations more favorably, and equal allocations less favorably, suggesting that concerns for the group come to play a stronger role in moral evaluation over time (Killen, Rutland, Abrams, Mulvey, \& Hitti, 2013).

Another possibility, however, is that social groups and morality are fundamentally intertwined with one another, such that as soon as notions of morality emerge, they are embedded within concerns for group membership. From this account, as young children learn about what behaviors are morally obligated and prohibited, they spontaneously view these obligations within the context of group membership. Then, the idea that groups function as moral boundaries should be evident in children's earliest moral evaluations and actions.

\section{Evidence from infancy}

Infants are sensitive to group membership within the first year of life. By 3 months, infants recognize differences between people based on race and gender (Bar-Haim, Ziv, Lamy, \& Hodes, 2006; Quinn, Yahr, Kuhn, Slater, \& Pascalis, 2002), and by 10-11 months, they can distinguish people based on the language they speak (Kinzler, Dupoux, \& Spelke, 2007, 2012) 
and whether they are an ethnic majority or minority (Singarajah et al., 2017). Infants also predict people's behavior on the basis of group membership: 7-month-olds expect social group members to act alike (Powell \& Spelke, 2013), 9-month-olds expect people to affiliate with each other if they speak the same language (Liberman, Woodward, \& Kinzler, 2017), and 12-month-olds expect people to preferentially choose to play with ingroup members over outgroup members (Ting, Dawkins, et al., 2019).

But do infants' representations of social groups include notions of morality? Infants do indeed appear to use social groups to structure their expectations of people's moral behavior. For example, by 13 months, infants expect people to avoid mild negative actions (e.g., knocking down part of a tower) toward ingroup members, but do not expect people to avoid these actions toward outgroup members (Ting, Dawkins, et al., 2019), and 12-month-olds expect two animate and agentive shapes of the same kind (e.g., two squares) to avoid harm to one another, but do not hold this expectation for shapes of different kinds (e.g., a square and a circle; Ting et al., 2019). Additionally, by 17 months, when presented with a person in need of assistance, infants expect others to help only if they share group membership with the target; if the target and the potential helper are in different groups, or group membership is unspecified, infants do not have clear expectations about whether others will help (Jin \& Baillargeon, 2017). Finally, by 18-20 months, infants expect people to prioritize ingroup members when allocating resources, particularly when resources are scarce (Baillargeon et al., 2015; Bian, Sloane, \& Baillargeon, 2018). Social groups also shape infants' expectations regarding how people will respond to moral transgressions: When shown instances of one person harming another, both 1-year-olds and 2.5-year-olds expect someone who shares group membership with the victim to harm (i.e., withhold help from) the transgressor in the future (Baillargeon et al., 2015; Ting, He, \& Baillargeon, 2019). 


\section{Evidence from early childhood}

The infancy research provides preliminary evidence that a consideration of social groups is an early-emerging feature of moral cognition, present within the first two years after birth. Yet, to truly show that groups serve as moral boundaries in early childhood, we would need explicit evidence that young children view intra-group and inter-group social interactions as governed by different sets of rules (i.e., that intra-group interactions fall under the domain of moral obligation, and inter-group interactions do not). For this evidence, we turn to our own work. In one set of studies (Rhodes \& Chalik, 2013) we tested the boundaries within which children interpret harmful actions as violating intrinsic, moral obligations. To test this question, we built on methods from the literature on Social Domain Theory (Smetana, 1981; Turiel, 1983), based on the premise that children view moral rules as universal, in that they apply regardless of the explicit rules in the immediate social context, unlike conventional rules, which only apply when explicitly stated in the local context. For example, children believe stealing to be a serious moral violation; as such, they say that stealing is wrong, even if it occurs at a school where the teachers say that stealing is allowed. On the other hand, children view wearing one's pajamas to school as a conventional violation that is only wrong when it is explicitly prohibited by teachers (i.e., it is perfectly permissible to wear pajamas to school on a day when the teachers say it is allowed; Smetana, 1981).

To apply this line of reasoning to the question of how groups factor into children's moral evaluations, we introduced 3- to 9-year-old children to two novel groups, marked by shirt color and label (i.e., the blue Flurps and the red Zazzes). As a baseline measure of children's evaluations, we asked them to rate instances of inter-group (e.g., Flurp-Zazz) and intra-group (e.g., Flurp-Flurp) harmful actions. For example, "How bad is it for a Flurp to tease another 
Flurp?" "How bad is it for a Flurp to harm a Zazz?" Next, we told children that there were no explicit rules in the immediate social context prohibiting these actions (e.g., "What if there was no rule in their school about teasing?") and asked them to evaluate the actions again. Before the information about the lack of a rule, children said it that it was "pretty bad" both for a Flurp to tease another Flurp and for a Flurp to tease a Zazz. But across all of the ages tested, how they responded to the rule information took into account the group memberships. For a Flurp teasing another Flurp, the rule information did not matter—children thought it was "pretty bad" for a Flurp to do this even if the action was not prohibited by a rule. Children thought that it was intrinsically wrong for someone to tease a group member, regardless of the rules. For a Flurp teasing a Zazz, however, we found a different pattern—although children initially thought this was "pretty bad," they thought it was less so if there were no rules about teasing. That is, children thought that how people are supposed to treat outgroups depends on the context, rather than on intrinsic obligations. Thus, children viewed moral obligations as governing how people should treat members of their own, but not other, groups. These studies represented the first clear evidence that young children view groups as moral boundaries within the first few years after birth.

The belief that groups mark moral boundaries also guides children's expectations of people's behavior in intergroup contexts. For instance, by age 3 and across childhood, children think that people are more likely to direct harm toward outgroup members than toward ingroup members, consistent with the ideas that people are obligated not to harm their ingroup members (Chalik \& Rhodes, 2018; Chalik, Rivera, \& Rhodes, 2014; Rhodes, 2012) and that people generally act in line with their obligations (Kalish \& Shiverick, 2004). Furthermore, by age 4, children predict that people will save ingroup members, rather than outgroup members, from 
dangerous events (Chalik \& Rhodes, 2018), and that when a group member is harmed, fellow group members will retaliate against the outgroup on the harmed individual's behalf (Chalik \& Rhodes, 2014). All of these predictions follow from the belief that groups structure how people should relate to one another.

As further evidence that these predictions stem from a belief in groups as moral boundaries, young preschoolers' social group-based predictions change across childhood, as their beliefs about moral obligation change. For example, young preschoolers do not expect that groups will structure prosocial behavior: 3 - to 5-year-olds believe that people are equally likely to perform prosocial behaviors (e.g., sharing toys) toward ingroup and outgroup members (Chalik \& Rhodes, 2018; Rhodes, 2012). This finding may seem counterintuitive given the other research we have reviewed, but it is consistent with certain perspectives in moral philosophy that indicate that among the fundamental behaviors that comprise human morality, prosocial behaviors, while valuable, are not morally obligated (Knobe, 2003; Leslie, Knobe, \& Cohen, 2006). By age 6 , however, children begin to predict that people will direct prosocial behaviors preferentially toward ingroup members (Rhodes, 2012). We believe that this change occurs because between the ages of 3 and 6 , children increasingly hear input to suggest that prosocial behaviors are obligatory among fellow group members. For example, in another set of studies, when parents and their 4-year-old children read stories involving harmful and prosocial actions that occurred both within and across social group boundaries, parents used moral language (i.e., language referring to moral concerns, such as fairness) to explain why people should be nice to fellow group members, but did not refer to moral concerns when explaining why people should be nice to members of other groups (Chalik \& Rhodes, 2015). These sorts of conversations may 
serve as a subtle source of input by which children come to see prosocial behaviors as constrained by moral obligations that only apply within group boundaries.

More direct evidence that input about moral obligation shapes children's predictions of intergroup behavior comes from a more recent set of studies (Chalik \& Dunham, 2018). Children were told about novel behaviors that either were or were not morally obligated, then were asked to predict whether those behaviors would play out within or across group boundaries. Specifically, children were told about a made-up behavior-wugging — and were told this behavior was either good or bad, and moral or non-moral (defined by whether it was or was not governed by rules in the immediate social context; Rhodes \& Chalik, 2013; Smetana, 1981). For example, if wugging was bad and moral, children were told, "It's bad for kids to wug each other. And even if the teachers say that you can wug somebody, you still shouldn't no matter what," whereas if wugging was bad and non-moral, children were told, "It's bad for kids to wug each other. But if the teachers say that you can wug somebody, you can if you want." Critically, these behaviors were introduced outside the group context. Then, children predicted whether characters were more likely to wug ingroup members or outgroup members. Across two studies, if wugging had been described as moral (i.e., consistently good or bad regardless of what teachers say), then children predicted that it would be constrained by group membership: If wugging was good, people would direct it toward ingroup members, and if wugging was bad, people would direct it toward outgroup members. Yet, if wugging had been described as nonmoral (i.e., only good or bad depending on what teachers say), then children thought that it was equally likely to occur among ingroup or outgroup members, regardless of whether it was good or bad. Thus, when a behavior is introduced as morally obligated, children spontaneously view 
those obligations as holding only within category boundaries, and they do not make a similar inference for behaviors that are outside the moral domain.

\section{Developmental origins}

Taken together, this body of work suggests that the belief that groups are moral boundaries is an early-emerging feature of human cognition. Already by age 3 , and perhaps earlier in infancy, children treat groups as marking moral boundaries. Young children view people as holding moral obligations to their own group members, and therefore use groups to predict, explain, and evaluate people's morally relevant actions. What is the developmental process by which this tendency originates in the first few years? Here we consider three broad possibilities: (1) that this tendency is an early emerging component of infants' "innate moral architecture," (2) that this tendency emerges from maturation-guided social interactional processes across the first three years, and (3) that these beliefs develop through a process of intuitive theory building across early childhood, scaffolded by a fundamental expectation that categories convey normative structure. Though not mutually exclusive, these perspectives differ in the extent to which children's beliefs about groups and morality arise from mechanisms specific to the social domain vs. more general conceptual processes, as well as the extent to which they are dependent on development and experience. We will consider each of these possibilities in turn.

\section{Groups as moral boundaries as part of a built-in first-draft of morality}

The evolutionary theories reviewed earlier indicate that morality evolved to coordinate behavior across unrelated individuals living in group contexts, and therefore imply that the tendency to treat groups as marking moral boundaries is part of a built-in, innate moral core (Boyd \& Richerson, 2009; Gintis et al., 2003; Greene, 2013; Rand \& Nowak, 2013; Trivers, 
1971). Yet, these perspectives are relatively vague with respect to the format, structure, or content of these built-in capacities. Addressing this gap, Baillargeon and colleagues have recently explored the earliest emergence of moral cognition by using patterns of infant looking behaviors to draw inferences about the conditions under which infants apply moral principles. In these studies, it is assumed that infants look longer at events that violate their basic expectations of the world; in the moral domain, then, infants are thought to look longer at events that are morally impermissible. This body of work has led to the proposal that human infants are born with a series of abstract principles that guide early moral cognition, including the principles of fairness, harm avoidance, authority, and most centrally to the present discussion, ingroup support (Dawkins, Ting, Stavans, \& Baillargeon, 2019; Ting, Dawkins, et al., 2019). According to this perspective, the principle of ingroup support has two corollaries: ingroup care and ingroup loyalty. Ingroup care includes the expectation that people should (and will) provide help and comfort to ingroup members and limit harm to ingroup members whenever possible. Ingroup loyalty includes the expectation that people prefer ingroup members over outgroup members and will reserve resources for ingroup members when resources are scarce.

From this perspective, when evaluating and predicting behavior, infants appeal to moral principles in cases where the relevant pre-conditions are met. Thus, infants will only recognize behaviors that are covered by the two corollaries of ingroup support (providing help, comfort, avoiding harm whenever possible, sharing scarce resources) as governed by moral principles if the agent and recipient meet the pre-condition of being members of the same group. Therefore, the notion that groups operate as moral boundaries — as determining whether people hold moral obligations to one another or not - is a built-in component of the abstract skeletal framework that underlies moral cognition. From this account, the role that groups play in shaping moral 
cognition is specialized to the moral domain and arises in the absence of specific experiences. Cultural experiences can then modulate how infants apply the principle of ingroup support (for instance, how they identify people as members of the same group or not) and how they ultimately weight this principle in relation to other moral principles (e.g., fairness, harm avoidance, and so on) across development, thus giving rise to cultural variation in moral reasoning among older children and adults (see also Haidt \& Joseph, 2004).

\section{Groups as moral boundaries as a consequence of collective intentionality}

Another view on how and why groups begin to function as moral boundaries in early development has been offered by Tomasello (2019) as part of his account of the nature and development of the human concept of obligation. From this view, during the first two years after birth, infants develop a sense of obligation first by participating in collaborative activities that involve shared intentionality (e.g., where children reason that, "you and I, as independent agents, intend to do this together"). As they participate in such interactions with social partners, children develop feelings of obligation toward their collaborative partners, wherein they feel that they owe it to their partners to follow through on their plans (and that their partners owe the same to them). These early feelings of obligation give rise to resentment and protest if people do not follow through on their jointly established goals. For instance, when children make a joint commitment to work together to achieve a certain set of resources, they do not feel that their task has been completed until both partners have met this goal, and they protest and try to reengage partners who try to drop-out part-way through a task, even if they are capable of achieving the goal by themselves (Kachel, Svetlova, \& Tomasello, 2018; Kachel \& Tomasello, 2019).

From this account, infants begin to show this understanding of shared intentionality, and to feel a sense of obligation toward their social partners (and believe that their partners are 
obligated toward them) between the first and second years of life. Then, at around age three, they generalize this notion of shared intentionality more broadly, to include broader senses of "we" (e.g., entire groups to which the child belongs) as well as a sense of the objective obligations that group members hold toward one another. At this time, children recognize that people hold special obligations to members of their broader cultural groups, simply by virtue of group membership. Thus, from this perspective, children generalize the sense of obligation that they develop in early dyadic interactions that involve shared intentionally outward, to shape their understanding of interactions and obligations among group members. From this account, children's belief that groups shape moral boundaries is the product of specific mechanisms for making sense of the social world and depends on children's earlier experiences in dyadic interactions (for a similar perspective, see Barragan \& Dweck, 2014). Note, however, that the experiences in dyadic interaction that are part of this account are thought to be such a universal feature of human experience that the experience-dependent nature of this proposal is not intended to account for cultural variation. Furthermore, the change that happens between the toddler years (ages 1-2) and the preschool years (ages 3-5) is thought to be mostly driven by the maturation that occurs in the context of social experiences, rather than those experiences themselves. Thus, from this account, children's beliefs do not result from any active role that children play in trying to understand the world around them.

\section{Groups as moral boundaries as a consequence of domain-general features of conceptual}

\section{development}

Here we will present an alternative view to the previous two, in which we suggest that the belief that groups constrain moral obligation arises out of the general processes that drive conceptual development across domains, rather than from dedicated mechanisms for social 
reasoning. This view has two key pieces: first, that children actively try to make sense of their environment by building and revising intuitive theories of the world; and second, that children have a general conceptual bias to expect categories to convey normative structure (e.g., to determine how category members are supposed to behave).

Categories structure cognition across domains, not only in the realm of social understanding. Across all areas of thought, representations of categories not only include descriptive information (e.g., that bees often sting, that cheetahs run fast, that spoons are used for eating and so on), but prescribe behaviors as well (that bees are supposed to sting by virtue of being members of their kind; Foster-Hanson \& Rhodes, 2019; Foster-Hanson, Roberts, Gelman, \& Rhodes, 2018; Haward et al., 2018; Prasada \& Dillingham, 2009). From infancy, these category representations are embedded in intuitive theories about the structure of the world, that specify the types of properties and characteristics that are prescribed by category membership (Gopnik \& Wellman, 2012; Wellman \& Gelman, 1992).

For instance, in the biological domain, children develop beliefs that species categories (e.g., membership in categories like "cheetah" or "bee") determine what types of food an animal eats, how it gets that food, how it reproduces, how it moves, its characteristic physical properties, and how it protects itself from predators (Gelman \& Coley, 1990; Gelman \& Markman, 1986, 1987; Gelman, Ware, \& Kleinberg, 2010). In the domain of human-made artifacts, children learn that artifacts are made for particular functions and often have characteristic shapes that facilitate those functions (Diesendruck, Markson, \& Bloom, 2003; Gelman \& Kremer, 1991; Greif, Kemler Nelson, Keil, \& Gutierrez, 2006; Kelemen, 1999). These abstract expectations about how categories are structured in particular domains allow categories to scaffold knowledge acquisition. They determine which features people expect to generalize across category members 
(e.g., that cheetahs are fast) and which are more idiosyncratic (e.g., that one cheetah might walk with a limp), as well as which features are explainable by direct appeal to category membership (e.g., that a particular skunk is stinky because it is a skunk) and which need to be explained by more extrinsic causes (e.g., that a particular skunk is dirty because it walked through the mud; Cimpian \& Markman, 2009).

As stated earlier, these expectations that children have about categories are not only descriptive, they are also normative in nature. To illustrate, Foster-Hanson and Rhodes (2019a) found that young children's biological concepts center on idealized prototypes-because they think that cheetahs are supposed to run fast, they think that the clearest and most informative representative of cheetahs is the very fastest in the world. Across development children begin to balance these prescriptive beliefs with the variation they encounter in the world (e.g., that cheetahs have variable running speeds) and to view more average exemplars (e.g., cheetahs with average speed for the category) as more representative and informative about what the category is like in general. These developmental changes in category representations have profound implications. Category examples that are thought to be the clearest representatives of their kinds (referred to as category prototypes) are the examples that people remember best, choose to learn from the most, and come to mind most easily (for review, see Murphy, 2002). Indeed, when children were asked to select examples of category members to learn from (e.g., out of a series of cheetahs that varied in running speeds) to figure out what a category is generally like, young children chose to learn from examples that showed the highest levels of prescribed properties (e.g., the two fastest cheetahs, the two stinkiest skunks). In contrast, older children and adults selected examples that covered variation (e.g., one fast cheetah and one slow one; FosterHanson, Moty, Cardarelli, Ocampo, \& Rhodes, 2019). This means that children's emphasis on 
prescriptive norms - the way that members of species categories, in this case, are supposed to be - biases how they learn new information about kinds.

These data illustrate that the beliefs that categories convey how their members are supposed to behave are not particular to the social domain. They are highly salient in biological representations as well (and also in representations of artifacts; Kelemen, 1999), particularly in early childhood. Indeed, to directly compare the extent to which normative beliefs shape children's representations of categories across domains, Foster-Hanson and colleagues (2018) asked children to determine whether category members that did not conform to group norms had done something "wrong." Similar stimuli and properties were shown to all participants. For instance, children were shown a group of category members who all ate a particular type of berry and then were asked to evaluate a category member who ate a different one. By condition, however, the categories were described as groups of animals or groups of people. In this study, children showed high levels of normative judgment. They often said that it was "not okay" for the category member to do something that conflicted with the group norm, and they made these judgments just as often for animal categories as for human social categories (see also Roberts, Gelman, \& Ho, 2017).

Thus, in early childhood, to guide learning across all areas of thought, children actively build hierarchical representations of the world around them. To illustrate, children might begin with a very abstract expectation: that there are different kinds of things in the world and that what kind of thing something is determines not only how it is, but how it should be. Underneath that very abstract theory of how the world is structured comes the more specific expectation that there are distinct categories of biological species, artifacts, and people. Each of those beliefs then branches into more specific expectations. For example, knowledge of biological species could 
include the idea that biological categories determine what foods an animal does (and should) eat. And from there that, for robins, for example, this means they do (and should) dig for worms. Because children are actively trying to make sense of their world through the lens of these developing representational structures, they do not need to learn about every single category from scratch each time they encounter a new one. For example, when they encounter an animal of a new species, they do not need to ask whether the animal eats food, reproduces, or moves. They can rely on their abstract expectations about animals and the nature of species kinds to infer that members of the new species will share characteristic ways of doing all these things, and go directly to figuring out what those are. Thus, children can learn a great deal from subtle cues and limited evidence.

From this perspective, the expectations that there are different kinds of people, and that categories determine what their members should do, are at high levels of abstraction in the conceptual hierarchy. Thus, just as children might learn that an animal species category determines what its members should eat, they can easily learn from limited evidence that a human social category determines how its members should behave, and particularly how they should behave towards one another. According to this account, children do not have to learn that groups mark moral boundaries from scratch. They already expect categories to prescribe the behaviors of category members. Thus, to then develop the belief that prescribed behaviors are bounded by social groups, children only need to infer which particular behaviors are prescribed. In the social domain, then, these prescribed behaviors exist in the form of social obligations among fellow social group members.

From this account, children assume that all norms (not just moral norms) are bounded by some type of category. Thus, once they learn that something falls under the scope of a norm (a 
prescribed behavior, or in the social domain, an obligation) then they assume there is a boundary on to whom it applies. Consistent with this perspective, in addition to moral norms, young children view social groupings as constraining other types of norms as well (Kalish \& Lawson, 2008; Kalish \& Shiverick, 2004; Roberts, Gelman, et al., 2017; Roberts, Guo, Ho, \& Gelman, 2018; Roberts, Ho, et al., 2017). For instance, children expect conventions to be shaped by group boundaries (e.g., conventions in dress, types of food that people eat, ritualistic behaviors, and so on). In fact, children expect the exact same behavior to generalize from one group member to another if it is described as a norm (e.g., if one "Flurp" is supposed to do a dance before bedtime, children will assume that other Flurps are supposed to do this too) but not if it is described as a preference (e.g., if one "Flurp" likes to do a dance before bedtime, children will not assume that other Flurps will like this too; Kalish, 2012). Further, in a category identification task, children assume that people who have the same norms, rather than the same preferences, are members of the same group (Kalish \& Lawson, 2008). As an additional illustration of the power of normative information particularly in early childhood, by age four, children assume that a person who is supposed to save people from fires, more than someone who really cares about saving people from fires, possesses the true properties of a firefighter (whereas adults judge the person who really cares as better exemplifying the category in this case; Foster-Hanson \& Rhodes, 2019b). This analysis of the origins of children's tendency to treat groups as marking moral boundaries suggests that children experience two key learning challenges in developing this belief. First, they need to identify the relevant social group boundaries. Second, they need to identify the relevant behaviors that are prescribed by category membership. How children learn to pick out relevant social group boundaries is beyond the scope of the present chapter (for reviews, see Dunham, 2018; Olson \& Dunham, 2010). In the experiments considered here, this 
piece of the problem is reduced for children because they are presented with clearly contrasting categories in the experimental paradigms themselves.

How children learn which behaviors are prescribed by category membership is an interesting question. Certainly, in the moral domain, children receive a fair amount of explicit prescriptive information. Yet subtle features of language may play a role here too. For instance, Chalik and Rhodes (2015) found that parents appeal to more abstract normative principles (e.g., saying things like, "it is important to be fair" to explain why people should share with one another) more for interactions among members of the same group than members of different groups. Note that in this case, parents said that people should share in both types of interactions; they just explained why this was the case in more normative terms when the interactions involved members of the same rather than different groups - thus perhaps implicitly communicating that although it is always nice to share, sharing is only obligatory among fellow social group members.

Perhaps even more subtly, generic claims about categories could also shape these beliefs. Generic claims describe what a category is like in abstract terms (e.g, "Cheetahs run fast" provides an abstract characterization of the category, even though individuals vary in how much they display the referenced property). Generics certainly convey descriptive information (e.g., they imply that a given property is higher among category members than among members of other similar categories; Gelman et al., 2010) as well as causal information (e.g., they are often interpreted as meaning that category membership plays a causal role in the manifestation of the property - for instance, that an individual cheetah runs fast because it is a member of the category "cheetahs"). Yet, generics also sometimes convey normative claims. That is, they describe how a situation ought to be, rather than how it actually is. 
To illustrate, consider this example, helpfully offered by the child of the second author, when he was three years old. After he looked up to see his mother starting to impatiently walk down the hallway of their apartment building while he continued to protest putting on his shoes, he called out: "Mama! Grown-ups wait for kids!" At this point, he was clearly not describing the current state of affairs; but instead, his view that members of the category "grown-ups" ought to behave a certain way. These situations are common, particularly involving the morally-relevant behavior of children. For instance, parents and teachers are considerably more likely to make generic claims like, “We don't hit!", when hitting is happening than when it is not. Thus, children can also take generic claims — particularly those that do not correspond to reality—as communicating ideals about the world and consequently use them to identify prescribed behaviors.

\section{Implications}

Of course, the three theoretical accounts described here need not be mutually exclusive. Children could have built-in abstract principles that guide their early moral reasoning, including an expectation of ingroup support. Their early experiences in dyadic interactions could lead them to develop a sense of shared agency and obligation to partners that then generalizes outward to shape more abstract representations of how obligation works among members of larger groups. Finally, children could develop these representations through an active process of intuitive theory-building. But even in the context of these other possible mechanisms, children's building of intuitive theories of the social world has important implications for the nature of early social cognition, as well as for how researchers, families, and educators might broaden moral socialization to allow children's feelings of responsibility and obligation to extend toward outgroup members. 


\section{For representations of early social categories and category-based induction}

The view that children treat groups as moral boundaries because they generally view categories as prescribing the behavior of their members clarifies the nature of early representations of social categories. This view suggests that children expect norms to generalize across groups more than other types of properties. As noted earlier, there is considerable evidence in support of this idea. Children expect the exact same property to generalize across members when it is described in normative terms (e.g., about what foods people are supposed to eat, what clothing they are supposed to wear, and so on) but not when it is described as reflecting preferences (e.g., what foods people like to eat or what they like to wear; Kalish, 2012). For moral behaviors this process takes a very particular form in which children appear to be more prone to use categories to predict whom someone will direct an action toward rather than whether a member of a particular group of people is likely to do a behavior. That is, just because one Flurp hits someone, children are unlikely to infer that another Flurp will do so, but if they are told that a Flurp hit someone, they $d o$ generate predictions about whom that action was directed at. Thus, clarifying the nature of early social categories allows us to understand the instances in which children will and will not rely on categories to understand the world around them. Doing so also establishes which components of social category representations are part of children's most basic beliefs about the structure of social groups, and which are dependent on other types of category-relevant learning. In particular, children's most basic social category representations do seem to support the morally relevant inferences described here about how people will act toward one another, but do not seem to give rise to the specific stereotypes that many children come to believe about social groups. For example, they do not include information about one group 
being more deserving of social power than others. These stereotypes appear to depend more heavily on the specific input that children receive in their environment across development.

\section{For how to engage in effective moral socialization}

The view that children treat social categories as marking moral boundaries, and that they do so because of general mechanisms of conceptual development, also provides guidance on how these effects might be reduced. Given that children in today's world constantly interact with people from a wide range of places and backgrounds, the view that people are obligated only toward fellow group members can be deeply problematic, easily leading children to act negatively toward outgroup members, or to accept intergroup conflict as an inescapable fact of life when they see it occur. Fortunately, the view that these beliefs arise from a process of intuitive theory-building suggests that by harnessing our understanding of the mechanisms of conceptual development, we can reduce children's reliance on social groups when thinking about moral obligation.

One potential avenue for encouraging children not to restrict their moral consideration to ingroup members (and thus to extend that same consideration toward outgroup members) relies on the linguistic forms of input that encourage children to view moral obligations as applying within group boundaries. One of these linguistic forms is the actual content that children hear. As described earlier, parents refer to moral concerns specifically to explain why people should be nice to fellow group members (Chalik \& Rhodes, 2015), implying that these moral concerns are particularly important within group boundaries. As a result, children expect that moral behaviors will play out along group lines (Chalik \& Rhodes, 2014, 2018; Chalik et al., 2014; Rhodes, 2012) to the extent that even for novel behaviors, as soon as children receive input to suggest that these behaviors are morally obligated, they spontaneously predict that they will be constrained 
by social group membership (Chalik \& Dunham, 2018). These finding suggest that if parents (and other adults) provide children with explicit input to suggest that moral obligations apply to everyone regardless of group membership, children may come to believe that moral behavior is not shaped by social group boundaries.

Additionally, using language to reduce children's reliance on social groups as they make sense of the world in general is a worthwhile effort. As stated earlier, generic language is a particularly influential linguistic device through which children develop beliefs about the stability and objectivity of category boundaries (Foster-Hanson, Leslie, \& Rhodes, 2019; Gelman et al., 2010; Rhodes, Leslie, Bianchi, \& Chalik, 2018; Rhodes, Leslie, \& Tworek, 2012). Particularly when thinking about human society, generic language about groups of people can encourage children to view those groups as objective ways of carving the social world. For example, hearing the sentence "Italians eat pasta" can lead a child to believe that people from Italy are an objectively different kind of people from people born in other places. Given that children build their expectations of moral behavior on top of underlying representations about the structure of social categories, as explained earlier, reducing the extent to which children hear generic language about social groups could make children less likely to use those groups to shape their moral understanding.

Another promising way to reduce children's reliance on social groups when thinking about morality is to interfere with the basic perceptual processes that cause children to view others as members of different groups. Recent work on individuation has shown that in both adults (Lebrecht, Pierce, Tarr, \& Tanaka, 2009) and children (Qian et al., 2017; Qian, Quinn, Heyman, Pascalis, \& Lee, 2019; Xiao et al., 2015), training people to recognize the identities of individual other-race faces reduces the implicit bias shown toward people from racial outgroups. 
It is thus possible that similar individuation training paradigms might reduce the extent to which children rely on ingroups and outgroups in shaping their expectations and evaluations of social behavior.

Recent work has also investigated ways to change children's feelings toward outgroup members in order to reduce intergroup bias across development. This work has yielded promising initial results, providing a number of suggestions as to how to reduce children's preferential treatment toward ingroup members and to increase children's feelings of positivity toward outgroup members. For example, increasing feelings of empathy toward outgroup members has been shown to reduce the likelihood that children will withhold help from members of that group as early as age 5 and across the elementary school years (Abrams, Van de Vyver, Pelletier, \& Cameron, 2015; Sierksma, Thijs, \& Verkuyten, 2014, 2015). Similarly, in adults, imagining a specific instance of helping someone else (episodic simulation; Gaesser, Shimura, \& Cikara, 2019) results in more willingness to help outgroup targets. Thus, similar methods may be effective in encouraging children to include outgroup members in their scope of moral consideration.

Finally, one particularly fruitful way of reducing children's focus on social group boundaries is intergroup contact. Interacting with outgroup members can reduce feelings of animosity toward those groups (Pettigrew \& Tropp, 2006). Indeed, children schooled in racially heterogeneous classrooms show less race-based bias than those from racially homogenous classrooms (Binder et al., 2009; McGlothlin \& Killen, 2010; Rutland, Cameron, Bennett, \& Ferrel1, 2005). Furthermore, even in cases where direct contact is not possible, extended contact - where children have not themselves had contact with outgroup members, but are aware of fellow group members who have - can reduce prejudice in school-age children (Cameron \& 
Rutland, 2006; Cameron, Rutland, \& Brown, 2007; Cameron, Rutland, Brown, \& Douch, 2006; Gaias, Gal, Abry, Taylor, \& Granger, 2018). Thus, putting children in either direct or extended contact with outgroup members can reduce the extent to which children care about group boundaries.

\section{Conclusion}

We have argued that a belief that social groups serve as moral boundaries is an earlyemerging feature of human cognition, arising from domain-general mechanisms of conceptual development. From an early age, children view social groups as sources of information about what people are like and how people should behave. Consequently, children use groups to define the boundaries within which people hold moral obligations toward one another. This view may be somewhat alarming, as it implies that valuing (or at least accepting) negativity toward outgroup members may be an inevitable consequence of early social cognition. Yet, it is also hopeful, as it suggests that an understanding of how children build intuitive theories of the world can inform successful interventions on these beliefs. Thus, an important next step for researchers, as well as for families, educators, and applied professionals, is to harness the knowledge we have gained about the development of social cognition and conceptual development more broadly and to use this knowledge to foster positive social relationships starting in early development. 


\section{References}

Abrams, D., \& Rutland, A. (2008). The development of subjective group dynamics. In S. R.

Levy \& M. Killen (Eds.), Intergroup attitudes and relations in childhood through adulthood: Studies in crime and public policy (pp. 47-65).

https://doi.org/10.1002/9781444390841.ch8

Abrams, D., Rutland, A., Cameron, L., \& Marques, J. M. (2003). The development of subjective group dynamics: When in-group bias gets specific. British Journal of Developmental Psychology, 21(2), 155-176. https://doi.org/10.1348/026151003765264020

Abrams, D., Rutland, A., Pelletier, J., \& Ferrell, J. M. (2009). Children's group nous: Understanding and applying peer exclusion within and between groups. Child Development, 80(1), 224-243. https://doi.org/10.1111/j.1467-8624.2008.01256.x

Abrams, D., Van de Vyver, J., Pelletier, J., \& Cameron, L. (2015). Children’s prosocial behavioural intentions towards outgroup members. British Journal of Developmental Psychology, 33(3), 277-294. https://doi.org/10.1111/bjdp.12085

Argo, N. (2009). Why fight? Examining self-interested versus communally-oriented motivations in palestinian resistance and rebellion. Security Studies, 18(4), 651-680. https://doi.org/10.1080/09636410903368920

Baillargeon, R., Scott, R. M., He, Z., Sloane, S., Setoh, P., Jin, K., ... Bian, L. (2015). Psychological and sociomoral reasoning in infancy. In M. Mikulincer, P. R. Shaver, E. Borgida, \& J. A. Bargh (Eds.), APA handbook of personality and social psychology, Volume 1: Attitudes and social cognition (pp. 79-150). https://doi.org/10.1037/14341-003

Bar-Haim, Y., Ziv, T., Lamy, D., \& Hodes, R. M. (2006). Nature and nurture in own-race face processing. Psychological Science, 17(2), 159-163. https://doi.org/10.1111/j.1467- 
9280.2006.01679.x

Barragan, R. C., \& Dweck, C. S. (2014). Rethinking natural altruism: Simple reciprocal interactions trigger children's benevolence. Proceedings of the National Academy of Sciences, 111(48), 17071-17074. https://doi.org/10.1073/pnas.1419408111

Bian, L., Sloane, S., \& Baillargeon, R. (2018). Infants expect ingroup support to override fairness when resources are limited. Proceedings of the National Academy of Sciences, 115(11), 2705-2710. https://doi.org/10.1073/pnas.1719445115

Binder, J., Zagefka, H., Brown, R., Funke, F., Kessler, T., Mummendey, A., ... Leyens, J. P. (2009). Does contact reduce prejudice or does prejudice reduce contact? A longitudinal test of the contact hypothesis among majority and minority groups in three european countries. Journal of Personality and Social Psychology, 96, 843-856.

https://doi.org/10.1016/j.ijintrel.2016.07.001

Boyd, R., \& Richerson, P. J. (2009). Culture and the evolution of human cooperation. Philosophical Transactions of the Royal Society B: Biological Sciences, 364(1533), 32813288. https://doi.org/10.1098/rstb.2009.0134

Brewer, M. B. (2007). The importance of being we: Human nature and intergroup relations. American Psychologist, 62(8), 728-738. https://doi.org/10.1037/0003-066X.62.8.728

Brewer, M. B., \& Kramer, R. M. (1986). Choice behavior in social dilemmas: Effects of social identity, group size, and decision framing. Journal of Personality and Social Psychology, 50(3), 543-549. https://doi.org/10.1037/0022-3514.50.3.543

Bruneau, E. G., Cikara, M., \& Saxe, R. (2017). Parochial empathy predicts reduced altruism and the endorsement of passive harm. Social Psychological and Personality Science, 8(8), 934942. https://doi.org/10.1177/1948550617693064 
Burkart, J. M., Hrdy, S. B., \& Van Schaik, C. P. (2009). Cooperative breeding and human cognitive evolution. Evolutionary Anthropology, 18(5), 175-186. https://doi.org/10.1002/evan.20222

Cameron, L., \& Rutland, A. (2006). Extended contact through story reading in school: Reducing children's prejudice toward the disabled. Journal of Social Issues, 62(3), 469-488. https://doi.org/10.1111/j.1540-4560.2006.00469.x

Cameron, L., Rutland, A., \& Brown, R. (2007). Promoting children's positive intergroup attitudes towards stigmatized groups: Extended contact and multiple classification skills training. International Journal of Behavioral Development, 31(5), 454-466. https://doi.org/10.1177/0165025407081474

Cameron, L., Rutland, A., Brown, R., \& Douch, R. (2006). Changing children's intergroup attitudes toward refugees: Testing different models of extended contact. Child Development, 77(5), 1208-1219. https://doi.org/10.1111/j.1467-8624.2006.00929.x

Chalik, L., \& Dunham, Y. (2018). Beliefs about moral obligation structure children's social category-based expectations. Child Development. https://doi.org/10.1111/cdev.13165

Chalik, L., \& Rhodes, M. (2014). Preschoolers use social allegiances to predict behavior. Journal of Cognition and Development, 15(1), 136-160. https://doi.org/10.1080/15248372.2012.728546

Chalik, L., \& Rhodes, M. (2015). The communication of naïve theories of the social world in parent-child conversation. Journal of Cognition and Development, 16(5), 719-741. https://doi.org/10.1080/15248372.2014.949722

Chalik, L., \& Rhodes, M. (2018). Learning about social category-based obligations. Cognitive Development, 48, 117-124. https://doi.org/10.1016/j.cogdev.2018.06.010 
Chalik, L., Rivera, C., \& Rhodes, M. (2014). Children's use of categories and mental states to predict social behavior. Developmental Psychology, 50(10), 2360-2367. https://doi.org/10.1037/a0037729

Cikara, M., Botvinick, M. M., \& Fiske, S. T. (2011). Us versus them: Social identity shapes neural responses to intergroup competition and harm. Psychological Science, 22(3), 306313. https://doi.org/10.1177/0956797610397667

Cikara, M., Farnsworth, R. A., Harris, L. T., \& Fiske, S. T. (2010). On the wrong side of the trolley track: Neural correlates of relative social valuation. Social Cognitive and Affective Neuroscience, 5(4), 404-413. https://doi.org/10.1093/scan/nsq011

Cimpian, A., \& Markman, E. M. (2009). Information learned from generic language becomes central to children's biological concepts: Evidence from their open-ended explanations. Cognition. https://doi.org/10.1016/j.cognition.2009.07.004

Clayton, S., \& Opotow, S. (2003). Justice and identity: Changing perspectives on what Is fair. Personality and Social Psychology Review, 7(4), 298-310. https://doi.org/10.1207/S15327957PSPR0704_03

Cohen, T. R., Montoya, R. M., \& Insko, C. A. (2006). Group morality and intergroup relations: Cross-cultural and experimental evidence. Personality and Social Psychology Bulletin, 32(11), 1559-1572. https://doi.org/10.1177/0146167206291673

Cooley, S., \& Killen, M. (2015). Children's evaluations of resource allocation in the context of group norms. Developmental Psychology, 51(4), 554-563. https://doi.org/10.1037/a0038796

Dawkins, M. B., Ting, F., Stavans, M., \& Baillargeon, R. (2019). Early moral cognition: A principle-based approach. In D. Poeppel, G. R. Mangun, \& M. S. Gazzaniga (Eds.), The 
cognitive neurosciences IV. Cambridge, MA: MIT Press.

Diesendruck, G., Markson, L., \& Bloom, P. (2003). Children's reliance on creator's intent in extending names for artifacts. Psychological Science, 14(2), 164-168.

https://doi.org/10.1111/1467-9280.t01-1-01436

Dunham, Y. (2018). Intergroup cognition. In The International Encyclopedia of Anthropology (pp. 1-8). https://doi.org/10.1002/9781118924396.wbiea1767

Foster-Hanson, E., Leslie, S. J., \& Rhodes, M. (2019). Speaking of kinds: How generic language shapes the development of category representations.

Foster-Hanson, E., Moty, K., Cardarelli, A., Ocampo, J. D., \& Rhodes, M. (2019). Developmental changes in strategies for gathering evidence about biological kinds.

Foster-Hanson, E., \& Rhodes, M. (2019a). Is the most representative skunk the average or the stinkiest? developmental changes in representations of biological categories. Cognitive Psychology, 110, 1-15. https://doi.org/10.1016/j.cogpsych.2018.12.004

Foster-Hanson, E., \& Rhodes, M. (2019b). Normative social role concepts in early childhood. Cognitive Science, 43(8), 1-18.

Foster-Hanson, E., Roberts, S. O., Gelman, S. A., \& Rhodes, M. (2018). Categories convey normative information across domains.

Frimer, J. A., Gaucher, D., \& Schaefer, N. K. (2014). Political conservatives' affinity for obedience to authority Is loyal, not blind. Personality and Social Psychology Bulletin, 40(9), 1205-1214. https://doi.org/10.1177/0146167214538672

Gaesser, B., Shimura, Y., \& Cikara, M. (2019). Episodic simulation reduces intergroup bias in prosocial intentions and behavior. Journal of Personality and Social Psychology. https://doi.org/10.1037/pspi0000194 
Gaias, L. M., Gal, D. E., Abry, T., Taylor, M., \& Granger, K. L. (2018). Diversity exposure in preschool: Longitudinal implications for cross-race friendships and racial bias. Journal of Applied Developmental Psychology, 59, 5-15. https://doi.org/10.1016/j.appdev.2018.02.005

Gelman, S. A., \& Coley, J. D. (1990). The importance of knowing a dodo is a bird: Categories and inferences in 2-year-old children. Developmental Psychology, 26(5), 796-804. https://doi.org/10.1037/0012-1649.26.5.796

Gelman, S. A., \& Kremer, K. E. (1991). Understanding natural cause: Children's explanations of how objects and their properties originate. Child Development, 62(2), 396-414. https://doi.org/10.1111/j.1467-8624.1991.tb01540.x

Gelman, S. A., \& Markman, E. M. (1986). Categories and induction in young children. Cognition, 23(3), 183-209. https://doi.org/10.1016/0010-0277(86)90034-X

Gelman, S. A., \& Markman, E. M. (1987). Young children's inductions from natural kinds: the role of categories and appearances. Child Development, 58(6), 1532-1541. https://doi.org/10.1111/j.1467-8624.1987.tb03864.x

Gelman, S. A., Ware, E. A., \& Kleinberg, F. (2010). Effects of generic language on category content and structure. Cognitive Psychology, 61(3), 273-301. https://doi.org/10.1016/j.cogpsych.2010.06.001

Ginges, J., \& Atran, S. (2009). What motivates participation in violent political action: Selective incentives or parochial altruism? Annals of the New York Academy of Sciences, 1167, 115123. https://doi.org/10.1111/j.1749-6632.2009.04543.x

Gintis, H., Bowles, S., Boyd, R., \& Fehr, E. (2003). Explaining altruistic behavior in humans. Evolution and Human Behavior, 24(3), 153-172. https://doi.org/10.1016/S1090$5138(02) 00157-5$ 
Gopnik, A., \& Wellman, H. M. (2012). Reconstructing constructivism: Causal models, Bayesian learning mechanisms, and the theory theory. Psychological Bulletin, 138(6), 1085-1108. https://doi.org/10.1037/a0028044

Graham, J., Haidt, J., \& Nosek, B. A. (2009). Liberals and conservatives rely on different sets of moral foundations. Journal of Personality and Social Psychology, 96(5), 1029-1046. https://doi.org/10.1037/a0015141

Greene, J. (2013). Moral tribes: Emotion, reason, and the gap between us and them. New York: Penguin Press.

Greif, M. L., Kemler Nelson, D. G., Keil, F. C., \& Gutierrez, F. (2006). What do children want to know about animals and artifacts? Domain-specific requests for information. Psychological Science, 17(6), 455-459. https://doi.org/10.1111/j.1467-9280.2006.01727.x

Hackel, L. M., Zaki, J., \& Van Bavel, J. J. (2017). Social identity shapes social valuation: Evidence from prosocial behavior and vicarious reward. Social Cognitive and Affective Neuroscience, 12(8), 1219-1228. https://doi.org/10.1093/scan/nsx045

Haidt, J., \& Graham, J. (2007). When morality opposes justice: Conservatives have moral intuitions that liberals may not recognize. Social Justice Research, 20(1), 98-116. https://doi.org/10.1007/s11211-007-0034-z

Haidt, J., \& Joseph, C. (2004). Intuitive ethics: How innately prepared intuitions generate culturally variable virtues. Daedalus, 133(4), 55-65.

Haidt, J., \& Joseph, C. (2007). The moral mind: How five sets of innate intuitions guide the development of many culture-specific virtues, and perhaps even modules. The Innate Mind, 3, 367-391. https://doi.org/10.1093/acprof:oso/9780195332834.003.0019

Haward, P., Wagner, L., Carey, S., \& Prasada, S. (2018). The development of principled 
connections and kind representations. Cognition, 176, 255-268.

https://doi.org/10.1016/j.cognition.2018.02.001

Jin, K. sun, \& Baillargeon, R. (2017). Infants possess an abstract expectation of ingroup support. Proceedings of the National Academy of Sciences, 114(31), 8199-8204. https://doi.org/10.1073/pnas.1706286114

Kachel, U., Svetlova, M., \& Tomasello, M. (2018). Three-year-olds' reactions to a partner's failure to perform her role in a joint commitment. Child Development, 89(5), 1691-1703. https://doi.org/10.1111/cdev.12816

Kachel, U., \& Tomasello, M. (2019). 3- and 5-year-old children's adherence to explicit and implicit joint commitments. Developmental Psychology, 55(1), 80-88. https://doi.org/10.1037/dev0000632

Kalish, C. W. (2012). Generalizing norms and preferences within social categories and individuals. Developmental Psychology, 48(4), 1133-1143. https://doi.org/10.1037/a0026344

Kalish, C. W., \& Lawson, C. A. (2008). Development of social category representations: Early appreciation of roles and deontic relations. Child Development, 79(3), 577-593. https://doi.org/10.1111/j.1467-8624.2008.01144.x

Kalish, C. W., \& Shiverick, S. M. (2004). Children's reasoning about norms and traits as motives for behavior. Cognitive Development, 19(3), 401-416. https://doi.org/10.1016/j.cogdev.2004.05.004

Kant, I. (1785). Grounding for the Metaphysics of Morals (3rd ed.). Indianapolis: Hackett Publishing Company.

Kelemen, D. (1999). Function, goals and intention: Children's teleological reasoning about 
objects. Trends in Cognitive Sciences, 3(12), 461-468. https://doi.org/10.1016/S13646613(99)01402-3

Killen, M., Rutland, A., Abrams, D., Mulvey, K. L., \& Hitti, A. (2013). Development of intraand intergroup judgments in the context of moral and social-conventional norms. Child Development, 84(3), 1063-1080. https://doi.org/10.1111/cdev.12011

Kinzler, K. D., Dupoux, E., \& Spelke, E. S. (2007). The native language of social cognition. Proceedings of the National Academy of Sciences, 104(30), 12577-12580. https://doi.org/10.1073/pnas.0705345104

Kinzler, K. D., Dupoux, E., \& Spelke, E. S. (2012). "Native" objects and collaborators: Infants' object choices and acts of giving reflect favoritism for native over foreign speakers. Journal of Cognition and Development, 13(1), 67-81. https://doi.org/10.1080/15248372.2011.567200

Knobe, J. (2003). Intentional action in folk psychology: An experimental investigation. Philosophical Psychology, 16(2), 309-324. https://doi.org/10.1080/09515080307771

Laham, S. M. (2009). Expanding the moral circle: Inclusion and exclusion mindsets and the circle of moral regard. Journal of Experimental Social Psychology, 45(1), 250-253. https://doi.org/10.1016/j.jesp.2008.08.012

Lama, D. (1998). The art of happiness. New York: Penguin Press.

Lebrecht, S., Pierce, L. J., Tarr, M. J., \& Tanaka, J. W. (2009). Perceptual other-race training reduces implicit racial bias. PLoS ONE, 4(1). https://doi.org/10.1371/journal.pone.0004215

Leslie, A. M., Knobe, J., \& Cohen, A. (2006). Acting intentionally and the side-effect effect: Theory of mind and moral judgment. Psychological Science, 17(5), 421-427. https://doi.org/10.1111/j.1467-9280.2006.01722.x 
Levine, M., Cassidy, C., Brazier, G., \& Reicher, S. (2002). Self-categorization and bystander non-intervention: Two experimental studies. Journal of Applied Social Psychology, 32(7), 1452-1463. https://doi.org/10.1111/j.1559-1816.2002.tb01446.x

Levine, M., \& Thompson, K. (2004). Identity, place, and bystander intervention: Social categories and helping after natural disasters. Journal of Social Psychology, 144(3), 229245. https://doi.org/10.3200/SOCP.144.3.229-245

Liberman, Z., Woodward, A. L., \& Kinzler, K. D. (2017). Preverbal infants infer third-party social relationships based on language. Cognitive Science, 41, 622-634. https://doi.org/10.1111/cogs. 12403

McGlothlin, H., \& Killen, M. (2010). How social experience is related to children's intergroup attitudes. European Journal of Social Psychology, 40(4), 625-634. https://doi.org/10.1002/ejsp.733

Meier, B. P., \& Hinsz, V. B. (2004). A comparison of human aggression committed by groups and individuals: An interindividual-intergroup discontinuity. Journal of Experimental Social Psychology, 40(4), 551-559. https://doi.org/10.1016/j.jesp.2003.11.002

Mill, J. S. (1854). On Liberty. London: Longman, Roberts, \& Green.

Moll, J., De Oliveira-Souza, R., \& Eslinger, P. J. (2003). Morals and the human brain: A working model. NeuroReport, 14(3), 299-305. https://doi.org/10.1097/00001756200303030-00001

Murphy, G. (2002). The Big Book of Concepts. https://doi.org/10.7551/mitpress/1602.001.0001

Olson, K. R., \& Dunham, Y. (2010). The development of implicit social cognition. In B. Gawronski \& K. Payne (Eds.), Handbook of implicit social cognition: Measurement, theory, and applications (pp. 241-254). New York: Guilford Press. 
Ongley, S. F., \& Malti, T. (2014). The role of moral emotions in the development of children's sharing behavior. Developmental Psychology, 50(4), 1148-1159. https://doi.org/10.1037/a0035191

Opotow, S. (2012). The scope of justice, intergroup conflict, and peace. In L. R. Tropp (Ed.), The Oxford Handbook of Intergroup Conflict (pp. 72-86). https://doi.org/10.1093/oxfordhb/9780199747672.013.0005

Pettigrew, T. F., \& Tropp, L. R. (2006). A meta-analytic test of intergroup contact theory. Journal of Personality and Social Psychology, 90(5), 751-783. https://doi.org/10.1037/0022-3514.90.5.751

Powell, L. J., \& Spelke, E. S. (2013). Preverbal infants expect members of social groups to act alike. Proceedings of the National Academy of Sciences, 110(41). https://doi.org/10.1073/pnas.1304326110

Prasada, S., \& Dillingham, E. M. (2009). Representation of principled connections: A window onto the formal aspect of common sense conception. Cognitive Science, 33(3), 401-448. https://doi.org/10.1111/j.1551-6709.2009.01018.x

Qian, M. K., Quinn, P. C., Heyman, G. D., Pascalis, O., Fu, G., \& Lee, K. (2017). Perceptual individuation training (but not mere exposure) reduces implicit racial bias in preschool children. Developmental Psychology, 53(5), 845-859. https://doi.org/10.1037/dev0000290

Qian, M. K., Quinn, P. C., Heyman, G. D., Pascalis, O., \& Lee, K. (2019). A long-term effect of perceptual individuation training on reducting implicit bias in preschool children. Child Development, 90(3), 290-305. https://doi.org/http://dx.doi.org/10.1037/dev0000290

Quinn, P. C., Yahr, J., Kuhn, A., Slater, A. M., \& Pascalis, O. (2002). Representation of the gender of human faces by infants: A preference for female. Perception, 31(9), 1109-1121. 
https://doi.org/10.1068/p3331

Rai, T. S., \& Fiske, A. P. (2011). Moral psychology is relationship regulation: Moral motives for unity, hierarchy, equality, and proportionality. Psychological Review, 118(1), 57-75. https://doi.org/10.1037/a0021867

Rand, D. G., \& Nowak, M. A. (2013). Human cooperation. Trends in Cognitive Sciences, 17(8), 413-425. https://doi.org/10.1016/j.tics.2013.06.003

Rhodes, M. (2012). Naïve theories of social groups. Child Development, 83(6), 1900-1916. https://doi.org/10.1111/j.1467-8624.2012.01835.x

Rhodes, M., \& Chalik, L. (2013). Social categories as markers of intrinsic interpersonal obligations. Psychological Science, 24(6), 999-1006. https://doi.org/10.1177/0956797612466267

Rhodes, M., Leslie, S. J., Bianchi, L., \& Chalik, L. (2018). The role of generic language in the early development of social categorization. Child Development, 89(1), 148-155. https://doi.org/10.1111/cdev.12714

Rhodes, M., Leslie, S. J., \& Tworek, C. M. (2012). Cultural transmission of social essentialism. Proceedings of the National Academy of Sciences, 109(34), 13526-13531. https://doi.org/10.1073/pnas.1208951109

Roberts, S. O., Gelman, S. A., \& Ho, A. K. (2017). So it is, so it shall be: Group regularities license children's prescriptive judgments. Cognitive Science, 41, 576-600. https://doi.org/10.1111/cogs. 12443

Roberts, S. O., Guo, C., Ho, A. K., \& Gelman, S. A. (2018). Children's descriptive-toprescriptive tendency replicates (and varies) cross-culturally: Evidence from China. Journal of Experimental Child Psychology, 165, 148-160. 
https://doi.org/10.1016/j.jecp.2017.03.018

Roberts, S. O., Ho, A. K., \& Gelman, S. A. (2017). Group presence, category labels, and generic statements influence children to treat descriptive group regularities as prescriptive. Journal of Experimental Child Psychology, 158, 19-31. https://doi.org/10.1016/j.jecp.2016.11.013

Rozin, P., Lowery, L., Haidt, J., \& Imada, S. (1999). The CAD triad hypothesis: A mapping between three moral emotions (contempt, anger, disgust) and three moral codes (community, autonomy, divinity). Journal of Personality and Social Psychology, 76(4), 574-586. https://doi.org/10.1037/0022-3514.76.4.574

Rutland, A. (2013). How do children learn to actively control their explicit prejudice? In M. R. Banaji \& S. A. Gelman (Eds.), Navigating the Social World (pp. 336-340). https://doi.org/10.1093/acprof:oso/9780199890712.003.0062

Rutland, A., Cameron, L., Bennett, L., \& Ferrell, J. M. (2005). Interracial contact and racial constancy: A multi-site study of racial intergroup bias in 3-5 year old Anglo-British children. Journal of Applied Developmental Psychology, 26(6), 699-713. https://doi.org/10.1016/j.appdev.2005.08.005

Rutland, A., \& Killen, M. (2017). Fair resource allocation among children and adolescents: The role of group and developmental processes. Child Development Perspectives, 11(1), 56-62. https://doi.org/10.1111/cdep.12211

Rutland, A., Killen, M., \& Abrams, D. (2010). A new social-cognitive developmental perspective on prejudice: The interplay between morality and group identity. Perspectives on Psychological Science, 5(3), 279-291. https://doi.org/10.1177/1745691610369468

Shweder, R. a., Mahapatra, M., \& Miller, J. G. (1990). Culture and moral development. In J. W. Stigler, R. a. Shweder, \& G. Herdt (Eds.), Cultural psychology: Essays on comparative 
human development (pp. 130-204). New York: Cambridge University Press.

Shweder, R. a., Much, N. C., Mahapatra, M., \& Park, L. (1997). The "big three" of morality (autonomy, community, divinity) and the "big three" explanations of suffering. In A. M. Brandt \& P. Rozin (Eds.), Morality and Health (pp. 119-169). Florence, KY: Taylor \& Frances.

Sierksma, J., Thijs, J., \& Verkuyten, M. (2014). Children's intergroup helping: The role of empathy and peer group norms. Journal of Experimental Child Psychology, 126, 369-383. https://doi.org/10.1016/j.jecp.2014.06.002

Sierksma, J., Thijs, J., \& Verkuyten, M. (2015). In-group bias in children's intention to help can be overpowered by inducing empathy. British Journal of Developmental Psychology, 33(1), 45-56. https://doi.org/10.1111/bjdp.12065

Singarajah, A., Chanley, J., Gutierrez, Y., Cordon, Y., Nguyen, B., Burakowski, L., \& Johnson, S. P. (2017). Infant attention to same- and other-race faces. Cognition, 159, 76-84. https://doi.org/10.1016/j.cognition.2016.11.006

Singer, P. (1981). The expanding circle: Ethics, evolution, and moral progress. Princeton, NJ: Princeton University Press.

Smetana, J. G. (1981). Preschool children's conceptions of moral and social rules. Child Development, 52(4), 1333. https://doi.org/10.2307/1129527

Staub, E. (1990). Moral exclusion, personal goal theory, and extreme destructiveness. Journal of Social Issues, 46(1), 47-64. https://doi.org/10.1111/j.1540-4560.1990.tb00271.x

Swann, W. B., Gómez, Á., Huici, C., Morales, J. F., \& Hixon, J. G. (2010). Identity fusion and self-sacrifice: Arousal as a catalyst of pro-group fighting, dying, and helping behavior. Journal of Personality and Social Psychology, 99(5), 824-841. 
https://doi.org/10.1037/a0020014

Tajfel, H., Billig, M. G., Bundy, R. P., \& Flament, C. (1971). Social categorization and intergroup behavior. European Journal of Social Psychology, 1(2), 149-178. https://doi.org/10.1002/ejsp.2420010202

Ting, F., Dawkins, M. B., Stavans, M., \& Baillargeon, R. (2019). Principles and concepts in early moral cognition. In J. Decety (Ed.), The social brain: A developmental perspective. Cambridge, MA: MIT Press.

Ting, F., He, Z., \& Baillargeon, R. (2019). Toddlers and infants expect individuals to refrain from helping an ingroup victim's aggressor. Proceedings of the National Academy of Sciences, 116(13), 6025-6034. https://doi.org/10.1073/pnas.1817849116

Tomasello, M. (2019). The moral psychology of obligation. Behavioral and Brain Sciences. Trivers, R. L. (1971). The evolution of reciprocal altruism. The Quarterly Review of Biology, 46(1), 35-57. https://doi.org/10.1086/406755

Turiel, E. (1983). The development of social knowledge: Morality and convention. Cambridge, UK: Cambridge University Press.

Voelkel, J. G., \& Brandt, M. J. (2019). The effect of ideological identification on the endorsement of moral values depends on the target group. Personality and Social Psychology Bulletin, 45(6), 851-863. https://doi.org/10.1177/0146167218798822

Wellman, H., \& Gelman, S. A. (1992). Cognitive development: Foundational theories of core domains. Annual Review of Psychology, 43(1), 337-375. https://doi.org/10.1146/annurev.psych.43.1.337

Xiao, W. S., Fu, G., Quinn, P. C., Qin, J., Tanaka, J. W., Pascalis, O., \& Lee, K. (2015). Individuation training with other-race faces reduces preschoolers' implicit racial bias: a link 
between perceptual and social representation of faces in children. Developmental Science, 18(4), 655-663. https://doi.org/10.1111/desc. 12241

Yamagishi, T., \& Kiyonari, T. (2006). The group as the container of generalized reciprocity. Social Psychology Quarterly, 63(2), 116. https://doi.org/10.2307/2695887 